Research Article

\title{
Study on Key Cost Drivers of Prefabricated Buildings Based on System Dynamics
}

\author{
Na Lou and Jingjuan Guo \\ School of Economics and Management, Beijing Jiaotong University, Beijing 100044, China \\ Correspondence should be addressed to Jingjuan Guo; jjguo@bjtu.edu.cn
}

Received 27 July 2020; Revised 12 October 2020; Accepted 12 October 2020; Published 30 October 2020

Academic Editor: Ossi Pesämaa

Copyright ( $) 2020 \mathrm{Na}$ Lou and Jingjuan Guo. This is an open access article distributed under the Creative Commons Attribution License, which permits unrestricted use, distribution, and reproduction in any medium, provided the original work is properly cited.

\begin{abstract}
The prefabricated building as a major initiative has been put forward by China in recent years to promote the transformation and upgrading of the construction industry, but its rapid development also faces high cost constraints. Therefore, it is necessary and urgent to study the key cost drivers and cost control paths of prefabricated buildings. Most of the current research focuses on the construction cost of prefabricated building as a static object. This article, on the other hand, regards the construction cost of prefabricated building as a dynamic formation process and conducts systematic research from product systems, technical systems, construction processes, and management modes. The influence factors of prefabricated building cost are defined and screened with the help of HSM and previous research results. A cause-and-effect model and cost control model of prefabricated building cost driver are established. Based on the model test of the actual project, the cost generation of prefabricated buildings is simulated. Through sensitivity analysis, key cost drivers of prefabricated building are identified and ranked as degree of design standardization, unit price, prefabrication rate, information technology level, transportation mode, labor level, machinery level, transportation distance, etc. Accordingly, corresponding strategies are proposed for the cost control of prefabricated buildings.
\end{abstract}

\section{Introduction}

In recent years, the prefabricated buildings have become the main direction for the transformation and upgrading of China s construction industry and the innovation of construction methods. The Guidance on Vigorously Developing Prefabricated Buildings issued by the general office of the state council in 2016 and the 13th five-year plan of the Ministry of Housing and Urban-Rural Development both regarded the development of prefabricated buildings as an important direction for the future development of the construction industry. The State Council of China even proposed to make prefabricated buildings account for $30 \%$ of new buildings within about 10 years [1]. Hence, prefabricated buildings in China face unprecedented opportunities and challenges.

However, at the same time, the high construction cost has been a major factor restricting the development of prefabricated buildings [2]. In general, when the prefabrication rate is more than $60 \%$, the unit cost can be increased by $25 \% \sim 30 \%$ [3]. People often attribute the high prefabricated building cost to high component price, large component transportation loss, and high hoisting machinery requirements [4]. However, the factors influencing prefabricated building cost are more diverse and the cost relationship is more complex. Therefore, it is necessary to study the complex relationship in the formation of prefabricated building construction cost. Poorly planned and constructed projects are more likely to incur higher operating costs, leading to negative impacts [5]. In addition, high cost is mainly due to stakeholder goals, conflicts of interest $[6,7]$, and the problem of path planning caused by the conflict of goals $[8,9]$. Moreover, it is necessary to systematically analyze the influence of various factors on the construction cost of prefabricated buildings and explore the prime path of cost control.

At present, the study of prefabricated construction costs mainly focuses on the cost comparative study with 
traditional cast-in-situ buildings $[10,11]$, the relationship between prefabricated rates and prefabricated construction cost $[12,13]$, the cost control methods of prefabricated buildings, etc. [14-16]. The above study has laid a certain foundation for the later research of the cost composition and control direction of prefabricated buildings. However, the present research mainly regards the cost of prefabricated buildings as a static research object and seldom considers the causes of the complicated relationship among cost drivers, the multiple feedback mechanism, and the influence of the external environmental changes. High cost is a common problem worldwide, with cost overruns occurring in about 90 percent of projects and 50 percent of construction projects in Asia [17], and cost overruns on prefabricated buildings remain unresolved [18]. Among them, poor planning tends to result in excessive cost [8]. Prefabricated construction is a construction method combining industrial production with on-site construction. It depends more on the maturity of the component processing industry, the standardization of design, and the efficient connection among component processing, transportation, storage, and installation. Therefore, it is necessary to carry out systematic research on product systems, technical systems, construction processes, management modes, and so on to comprehensively control the cost of fabricated buildings [19].

In view of the rational man hypothesis, prospect theory holds that subjective factors make judgment and reasoning different from person to person. The more complex the problem is, the less subjective decisions can be taken, and more standardized decisions are needed. Therefore, this paper uses system dynamics to carry out cost control and decision-making in a standardized way. System dynamics is a tool for the analysis of complex dynamic feedback systems. This method combines qualitative and quantitative methods and is very effective for the study of nonlinear and high-order complex time-varying systems. This study uses system dynamics to study the cost factors and cost control of prefabricated buildings. Although the maintenance cost is essential, the prefabricated buildings in China are in the promotion period, and it is difficult to measure the dynamic feedback relationship among various cost factors during the operation and maintenance period. Moreover, construction cost is the cost that builders pay most attention to $[20,21]$. Performance feedback in the construction process can have a positive impact on the optimization of the construction process [22]. Therefore, this paper takes the construction cost as the research object by analyzing and screening the influence factors of prefabricated building construction cost. It establishes system dynamics model of cost control, simulates the formation process of prefab building construction cost, and then analyzes the sensitivity factors of construction cost, so as to put forward the corresponding strategies for the cost control of prefabricated building.

\section{Literature Review}

At present, the research on prefabricated building cost is mostly based on the cost composition. Li et al. [11], through a comparative analysis of the cost composition of prefabricated buildings and traditional cast-in-place buildings, concluded that the high cost of civil construction of prefabricated buildings, especially the high cost of materials, was the main reason for the high cost of prefabricated buildings. Hong et al. [23] further discussed the driving factors leading to the increase of prefabrication cost and found that the prefabrication rate was almost linearly correlated with the prefabricated construction cost. In terms of cost influencing factors, Liu and Chen [12] established the cost structure of prefabricated building, and Jin et al. [4] obtained six key cost-influencing factors such as construction level, construction maturity, standard, production level, capability, and management level of prefabricated components through questionnaire survey and factor analysis. In the above studies, the cost composition and main influencing factors of prefabricated buildings were well sorted out, but cost drivers and their influence on the cost formation process were not considered. In other words, the relationship between cost drivers and costs was not established to quantify the impact.

In terms of cost control, Anvari et al. [14] applied GA to optimize the process of production, transportation, and assembly of components to control costs. Chen et al. [24] optimized the production technology of prefabricated components through the process reengineering of prefabricated components. Wang and Wang [25] proposed the strategy of taking BIM as the center, promoting stakeholder communication, mitigating key schedule risks, and the interaction behind the risk network to reduce costs. Hammad et al. [16] applied BIM to establish a framework to analyze social, environmental, and economic factors of prefabricated buildings. Ham et al. [26] studied the performance potential of BIM-assisted identification of single design errors and proposed a proposal to reduce costs by controlling design errors based on BIM [27]. Li et al. [28] combined BIM and RFID technologies to achieve the goal of refined prefabricated building construction management. The above studies on cost control mainly put forward corresponding improvement strategies from different aspects such as design, production, transportation, installation, and application of information technology, but failed to systematically analyze or identify the most critical control path. Feedback path is an important aspect of cost analysis [22].

To sum up, the existing research is limited to the static cost analysis and cost control in the link of a certain research. However, the cost of prefabricated building is different from that of traditional manufacturing industry and construction industry. The cost influence factors are more diverse, and the cost relationship is more complex. The cost increase may be caused by different reasons, or a single reason may induce multiple cost increases. In short, the cost increment is the result of the dynamic interaction of cost drivers, and it is necessary to analyze the impact of a factor on the whole from a systematic perspective. System dynamics is a method to study the overall behavior of the whole system by analyzing the feedback structural relationship between variables in the social and economic system [29]. In the field of engineering construction, engineering cost analysis has been applied. For example, Lyneis et al. [30], Ning and Wang [31], and He and Cheng [32] all used system dynamics tools to analyze cost 
factors in engineering projects. Based on the system dynamics, this paper focuses on the relationship among the stages of prefabricated building design, production, transportation, and assembly and simulates the dynamics of prefabricated building cost system under time changes by combining the influence of policies and standards and other external links so as to find a more realistic cost control path.

\section{Establishment of Cause-and-Effect Model of Prefabricated Buildings Cost}

\subsection{Analysis of Cost Influencing Factors}

\subsubsection{Definition of Cost Influencing Factors. Different from} traditional buildings, prefabricated buildings maintain not only the characteristics of traditional site construction, but also have the characteristics of industrial production. Besides, the cost factors are more diversified. This paper only considers the incremental cost of prefabricated buildings, which is different from traditional cast-in-place buildings. Hall's three-dimensional structure model is a coordination tool consisting of logical, time, and knowledge dimensions and an analysis tool for the relationship between managers and programs [33]. In order to avoid the deviation of cost factor selection due to individual subjective decision, standardized means are adopted. Based on the three-dimensional model, a prefabricated building cost analysis model can be established as shown in Figure 1. Through the cross-exploration of the time dimension, the logic dimension, and the knowledge dimension, the corresponding cost influencing factors are defined.

From the perspective of time dimension, the construction of prefabricated buildings is mainly divided into design and construction stages. Among them, the construction stage includes component production, transportation, and assembly stages. In terms of logic dimension, the process of prefabricated building construction includes target determination, analysis, feedback optimization, decision-making, and implementation. From the perspective of knowledge dimension, it is necessary to include professional knowledge such as management and operation and information technology and emphasize the control of quality, schedule, and cost. According to the three-dimensional model, the cost influencing factors of prefabricated buildings are analyzed with time dimension as the main stage direction:

(1) Research, Development, and Design Stage. In the $\mathrm{R} \& \mathrm{D}$ and design stage of prefabricated buildings, technical planning, design, optimization, and decision-making should be carried out on the basis of design standards and specifications. Compared with traditional cast-in-place buildings, prefabricated buildings add technical planning, research and development of new components, standardized design, component separation design, mold design, assembly and construction design, etc. In addition, the design should be fully communicated with professional design teams and component manufacturers to ensure professional collaboration and component production quality. In order to achieve the effect of design-processing-assembly integration, the special requirements of production, transportation, and field installation should be taken into account. At the same time, it is also necessary to use information technology to further improve the standardization, accuracy, and management efficiency of the design. All of the above stages will affect the cost of prefabricated buildings to some extent.

(2) Construction Stage. In the process of component production, component production technology level, component standardization degree, component factory scale, component order quantity, and other factors will affect component production cost. In the transportation link, different transportation schemes bring different transportation costs, and there are inevitable losses in the transportation process. In the construction and assembly process, it will also involve the management of the site, the level of artificial machinery, the formulation and implementation of the construction plan, and other factors. In addition, in the whole construction stage, it is necessary to use information technology means to strengthen the component procurement, distribution, storage, and installation of fine, standardized management, to improve the construction quality.

3.1.2. Cost Influencing Factors Screening. There are many studies on the cost composition of prefabricated buildings in relevant literature. Through the analysis of the previous research results, the cost influencing factors of prefabricated buildings can be further studied/investigated. For example, decision-making cost and design cost will be generated in the design stage of prefabricated building, and prefabricated component cost, transportation cost, component prefabricated cost, and site construction cost will be generated in the construction stage [12]. In terms of cost composition, studies have shown that the cost of prefabricated components accounts for $26 \%$ to $60 \%$ of the total cost, followed by labor cost (17\%-30\%) and transportation cost (10\%) [23]. In the design stage, the designer's experience level, design standardization, and the integrity of relevant design specifications will affect the design level, and the occurrence of design errors will lead to the rework and delay of the project [26]. The scale and location of the component plant are closely related to the cost of component production and transportation. Secondly, the influence of manual technology and specification [27] must be studied. In the final construction and assembly stage, the standardization and unified design of components in the early stage will facilitate the site management. The site work also needs to consider unloading, protection, and storage, supplemented by the assistance of construction technology and machinery [23]. In addition, the prefabrication rate, type of prefabricated components, and market maturity are the key factors influencing the cost-effectiveness of China's prefabricated construction market [23]. Building information modeling (BIM) is a technology that can be effectively applied to 


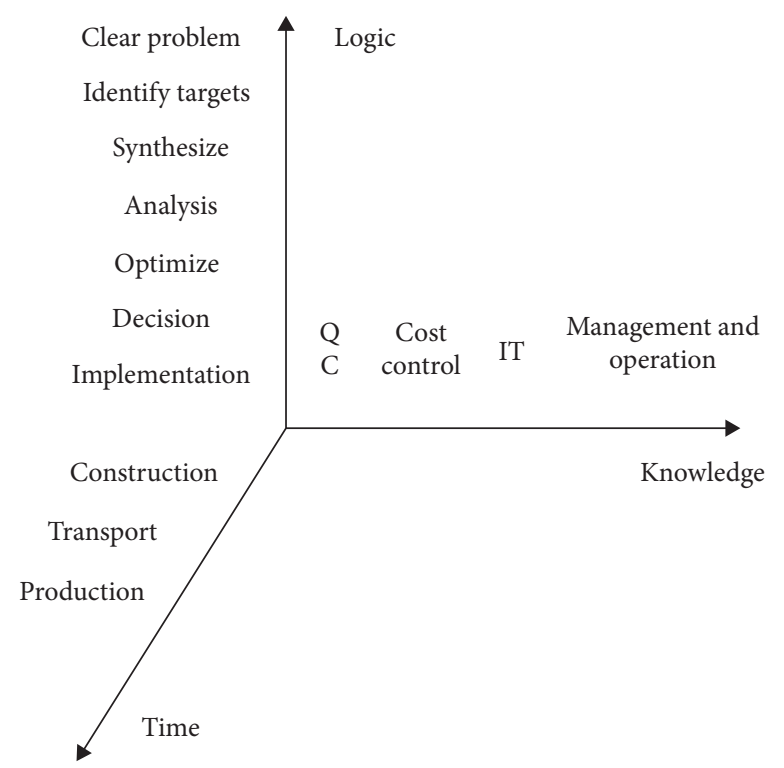

FIGURE 1: HSM of life cycle cost for prefabricated buildings.

different parts of the construction project [26]. Based on the above analysis, combined with the scope defined above and Jin et al. [4]'s research on cost-influencing factors, factors influencing the construction cost of prefabricated buildings are screened out in Table 1.

3.2. Establishing the Basic Model of Causality. The causal relationship between each selected factor is further analyzed and established, as shown in Figure 2. First of all, from design level, prefabrication rate to component production and manufacturing, transportation, storage, and assembly, every link will affect the construction cost, and policy orientation will also indirectly affect the construction cost by affecting the construction environment of prefabricated buildings. Secondly, the design and construction quality of the project are an indirect variable that affects the cost, and the management level, information technology application level, and so on will also affect the design and construction quality. Based on the analysis of cost influencing factors and impact paths, a causal diagram of prefabricated building cost factors can be established, as shown in Figure 2.

Around the center of construction cost, Vensim is applied to conduct modeling, and it is concluded that there are multiple feedback paths in causality, and multiple feedback paths reveal the complexity of the system. The main feedback loops in causality are as follows:

Construction cost $\longrightarrow$ The quality of the project$\longrightarrow$ Engineering change $\longrightarrow$ Component order quantity $\longrightarrow$ Component manufacturing $\longrightarrow$ Construction cost

Construction cost $\longrightarrow$ The quality of the project$\longrightarrow$ Engineering change $\longrightarrow$ Component order quantity $\longrightarrow$ Transportation $\quad$ loss $\longrightarrow$ Component transportation $\longrightarrow$ Construction cost
Construction cost $\longrightarrow$ The quality of the project$\longrightarrow$ Engineering change $\longrightarrow$ Component order quantity $\longrightarrow$ Component manufacturing $\longrightarrow$ Component quality $\longrightarrow$ Component assembly $\longrightarrow$ Construction cost

Component order quantity $\longrightarrow$ Component manufacturing $\longrightarrow$ Component $\quad$ quality $\longrightarrow$ Engineering quality $\longrightarrow$ Engineering change $\longrightarrow$ Component order quantity

Among the loops, the construction cost will affect the project quality, and the reduction of project quality will lead to more engineering changes, which will bring about changes in the order quantity of engineering components, thus affecting the production cost of components and finally the construction cost. The number of components corresponds to the cost of component manufacturing and other factors and then to the engineering quality. The poor engineering quality leads to engineering changes, which ultimately affects the number of components.

\section{Cost Control Model and Simulation Analysis of Prefabricated Building}

\subsection{Establishing the Basic Control Model}

4.1.1. Stock Flow Diagram. In order to further clarify the feedback form and control law of the system, the variable properties are further distinguished on the basis of causal loop diagram, after which is drawn the system stock flow diagram. In order to simplify the analysis, the design level in Figure 2 can be replaced with design cost, equipment mechanization level with unit price of machinery, artificial technology level with artificial unit price, policy subsidies with subsidies, and component market maturity with component market unit price. Take transportation, production, and assembly process as the flow, take component 
TABLE 1: Factors influencing the construction cost of prefabricated buildings.

\begin{tabular}{|c|c|}
\hline Stage and link & Construction cost impact factor \\
\hline \multirow{4}{*}{ Design } & Designer experience \\
\hline & $\begin{array}{c}\text { Precast housing design specifications and } \\
\text { standards }\end{array}$ \\
\hline & Standardization of component design \\
\hline & Prefabrication rate \\
\hline \multirow{5}{*}{ Production } & Component order quantity \\
\hline & $\begin{array}{l}\text { The size and capacity of the state of the system } \\
\text { Technical level of production workers }\end{array}$ \\
\hline & $\begin{array}{l}\text { Production specifications and standards for } \\
\text { components }\end{array}$ \\
\hline & Member type \\
\hline & Market maturity \\
\hline \multirow{3}{*}{ Transportation } & Distance \\
\hline & Methods \\
\hline & Transport losses \\
\hline Storage & Storage time \\
\hline \multirow{2}{*}{ Assembly } & Managerial and worker experience \\
\hline & $\begin{array}{l}\text { Degree of construction mechanization } \\
\text { Information technology level }\end{array}$ \\
\hline \multirow[t]{2}{*}{ Other } & The management level \\
\hline & Policy norm \\
\hline
\end{tabular}

inventory, component production, transportation and installation costs, and planned costs as the inventory, and take construction cost as the sum of the inventory. Based on the causal relationship, the stock flow diagram is established as shown in Figure 3.

4.1.2. Cost Control Model Establishment. By using Vensim, the cost control model is established, the relationship between factors in the model is defined, and the system operation results are simulated. In order to quantify the influence of factors, score and assign some variables, such as design level, standardization level, information level, transportation mode, and other factors. Here, the prefabrication rate and construction cost are treated in a linear relationship (see [23]), where the linear proportional coefficient is 0.56 [23]. According to the current prefabricated building incentive policy, when the prefabricated rate is more than $50 \%$, the subsidy will be added. The assembly construction cost model finally established is as follows:

$$
\begin{aligned}
C & = \begin{cases}f(i) \times \sum c-a, & i \geq 0.5, \\
f(i) \times \sum c, & i<0.5,\end{cases} \\
f(i) & =e \times i+f,
\end{aligned}
$$

where $C$ is construction costs, $\sum c$ is design stage cost, cost of production, transportation, and installation of components such as aggregation, $f(i)$ is the corresponding linear function related to the rate of prefabricated, $i$ is precast rate, $e$ and $f$ are constant, $a$ is the corresponding amount of subsidies.
(1) Main Models in the Design Stage. The design cost of castin-place buildings is generally $30 \mathrm{yuan} / \mathrm{m}^{2}$, and the cost of prefabricated buildings is about $30 \%$ more than that of castin-place buildings [15]. According to the empirical data, the design defect rate is within 5\%. The standardization degree, prefabrication rate, and information technology level of components will have a positive impact on the design level. According to the value method of Jia [34], the value range of standardization degree is $[0,1]$, and the value range of information technology level is $[0,1]$. Then, the main models in the design stage are as follows:

$$
\begin{aligned}
D(x) & =A X+b, \\
\omega & =f(D) \times \alpha, \\
f(D) & =\varepsilon \times D,
\end{aligned}
$$

where $D(x)$ is the level of deepening design, $A$ is the coefficient matrix, $x$ is $\left\{x_{1}, x_{2}, \ldots, x_{n}\right\}$, including variables such as standardization degree and information level, and $b$ is a constant. $\alpha$ is the maximum value of the design defect rate, $f(D)$ is the linear relation function related to the design level, $\omega$ is the design defect rate, and $\varepsilon$ is the correlation coefficient that can be $1 / 3$ and convert the deepened design into the radio.

(2) Main Models in the Component Production Stage. The main models of component production stage are as follows:

$$
\begin{aligned}
C_{p} & =Q \times P, \\
Q & =\sum_{i=1,2, \ldots, n} q_{i} \times \lambda, \\
q_{1} & =Q \times \omega, \\
q_{2} & =Q \times \delta,
\end{aligned}
$$

where $C_{p}$ is the accumulation of component production cost, $Q$ is the number of components, $P$ is the unit price of components, $q_{i}$ is the corresponding number of components, including component order quantity, transportation loss, and engineering change, $\lambda$ is the capacity coefficient of the prefabricated component factory, $q_{1}$ is the engineering change, $\omega$ is the design defect rate, $q_{2}$ is the transportation loss, and $\delta$ is the transportation loss rate.

(3) Main Models in the Installation Stage. Installation costs include labor cost and machinery cost, in which the number of mechanical shifts and labors is related to the number of components installed, and the relationship coefficient is taken from the prefabricated building quota. The main models in the installation stage are as follows:

$$
\begin{aligned}
C_{\text {pre }} & =\sum p_{\text {pre }}, \\
p_{\text {pre }} & =p^{\prime} q, \\
q & =Q \times \beta,
\end{aligned}
$$

where $C_{\text {pre }}$ is installation costs of cumulants, $\sum p_{\text {pre }}$ is the sum of the components of cost, including labor, and machinery use fee, $Q$ is the number of units of each item, $p^{\prime}$ is 


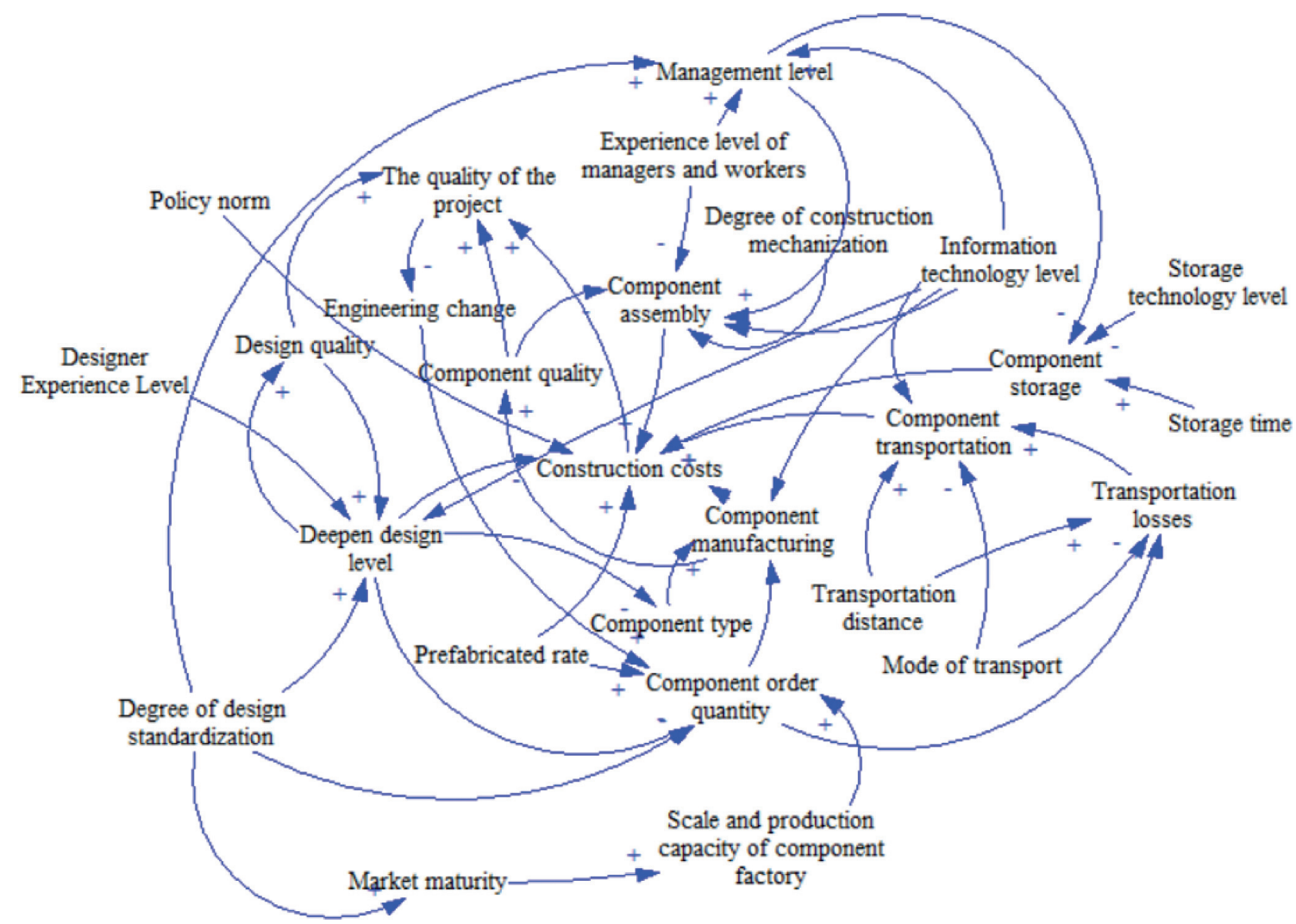

FIgURE 2: Cause-and-effect diagram of assembly construction cost.

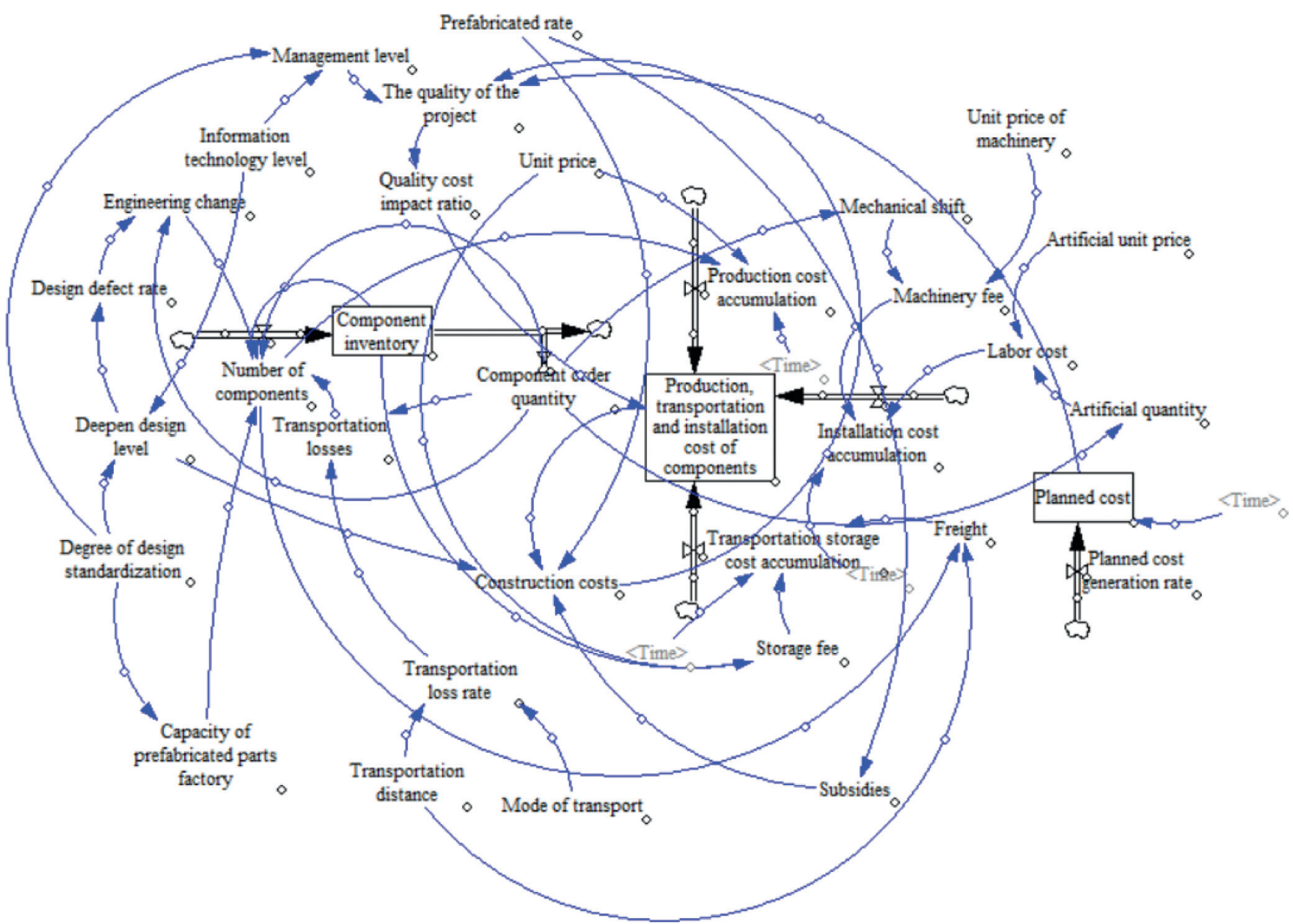

FIGURE 3: Flowchart of cost control stock of prefabricated building construction. 
the unit price of each item, $q$ is the number of components, and $\beta$ is the relationship coefficient of the corresponding quota.

(4) Main Model of Transportation and Storage Cost. Transportation and storage costs include storage costs and transportation costs. According to the research results, the proportion of storage costs is 0.4 [15], and the transportation costs are calculated according to the national standard of vehicle transportation costs. The main models are established as follows:

$$
\begin{aligned}
C_{\mathrm{tr}} & =\sum p_{\mathrm{tr}}, \\
p_{\mathrm{tr} 1} & =p_{\mathrm{tr} 1}^{\prime} \times q_{\mathrm{tr} 1} \times \gamma_{1}, \\
p_{\mathrm{tr} 2} & =Q \times L \times \gamma_{2},
\end{aligned}
$$

where $C_{\mathrm{tr}}$ is transportation storage costs of cumulants, $\sum p_{\mathrm{tr}}$ is the sum of each item cost including transportation cost and storage cost, $p_{\operatorname{tr} 1}^{\prime}$ is price, $q_{\text {tr } 1}$ is storage quantity, $\lambda, \gamma_{1}$, and $\gamma_{2}$ are the corresponding cost coefficients of transport and storage, respectively, $Q$ is the number of components, and $L$ is transportation distance.

(5) Other Models. According to Taguchi quality theory and related studies [35], the relationship between quality and cost is parabolic, and quality is related to management level and information technology level. The relationship model obtained is as follows:

$$
\begin{aligned}
\theta & =g Q_{u}^{2}+h Q_{u}+k, \\
Q_{u} & =f(M, I),
\end{aligned}
$$

where $\theta$ is the relation ratio between quality and cost, $Q_{u}$ is the engineering quality level, $g, h$, and $k$ are the coefficients of the quality equation, and $f(M, I)$ is the function of quality and management level $(M)$ and information technology level $(I)$.

Some parameters in the model are set as shown in Table 2.

4.2. Cost Control Model Test. Five practical assembly project cases have been selected to simulate the model. Among the five cases, case 1 is located in Jinan, Shandong; cases 2, 3, and 4 are located in Haidian, Tongzhou, and Changping, Beijing, and case 5 is located in Nanjing, Jiangsu. The basic data of the five cases are shown in Table 3.

The data of five cases have been substituted into the model. Then the model fitting results have been obtained through Vensim model simulation operation, and the fitting results have been compared with the actual engineering construction costs, as shown in Table 4. The data show that the fitting deviation is less than $10 \%$, so the above control model is available.

\subsection{Simulation and Analysis of Important Influencing Factors}

4.3.1. Cost Control Simulation. Using this model and the data of a prefabricated building project in Beijing, we set the first month as the time for construction decision and design and the next 28 months as the construction period. After relevant data are input into the model, the curve of the whole project construction period is obtained as shown in Figure 4.

As can be seen from the graph, the project has a period of rising cost in the early stage of the construction phase, and the cost also keeps rising rapidly for a long time after the construction period. However, due to the combined effect of quality, transportation, and other factors, the increase is in a state of fluctuation.

4.3.2. Analysis of Simulation Results. Using Vensim composite simulation, we can find the uncertainties input into the system and measure the impact of uncertainties on the construction cost by changing the values of the uncertainties and observing the changes in the construction cost curve. The change rates were taken as $\pm 5 \%$ and $\pm 10 \%$, respectively, and the final construction cost being the index to calculate the corresponding sensitivity coefficient. The calculation formula is as follows:

$$
E=\left|\frac{C_{i}-C_{0}}{C_{0}} \div \beta\right|,
$$

where $E$ is the sensitivity coefficient, $C_{i}$ is the corresponding project construction cost, $C_{0}$ is the original project construction cost, and $\beta$ is the change rate.

In comprehensive comparison of sensitivity coefficients, the results are given in Table 5 .

The simulation results finally confirm eight related factors, which correspond to the influencing factors. The unit price of labor and the unit price of machinery correspond to the level of labor and machinery and the corresponding policies and regulations of subsidy. The final results of influencing factors are as shown in Table 6.

According to the results, the degree of standardization has the most significant impact on the construction cost, with a wide range of impact, including market maturity, design, management, and other aspects. The research results of Hong et al. [23] and Jin et al. [4] show the great impact of market maturity, which proves the important role of largescale and standardized construction in prefabricated building market from the side. Therefore, it is necessary to perfect the whole industrial chain, increase the number of component factories, improve production capacity, and form scale effect from a macro perspective.

Secondly, component unit price and prefabrication rate have a great impact on building cost. This paper calculates the incremental cost of prefabricated buildings compared with ordinary cast-in-place buildings. Since the component itself has the most direct impact on the construction cost, the unit price and prefabrication rate of the component reflect the incremental cost brought by the component itself. In the calculation of the prefabrication rate, when the prefabrication rate is too high, over $80 \%$, its cost will suddenly rise. This might lead us to wonder, "Do we need to go for too high a prefabrication rate?." In order to control the cost in this aspect, it is necessary to reduce the loss from the perspective 
TABLE 2: Basic equation parameters.

\begin{tabular}{lc}
\hline Parameter & Values or ranges of values \\
\hline Linear correlation coefficient between prefabrication rate and construction cost & 0.56 \\
Subsidies & 180 yuan $/ \mathrm{m}^{2}$ \\
Design defect maximum & $5 \%$ \\
Transportation loss rate & $1 \%$ \\
Artificial rate & 1.084 \\
Mechanical rate & 0.0439 \\
Component storage cost coefficient & 0.4 \\
Component transportation cost coefficient & 0.21 yuan/piece-km \\
Mass equation coefficients $g, h$, and $k$ & $0.4,0.8,1$ \\
Engineering quality level & {$[0,1]$} \\
Degree of design standardization & {$[0,1]$} \\
Capacity coefficient of the prefabricated component factory & {$[0,1]$} \\
Information technology level & {$[0,2]$} \\
Deepen design level & {$[0,3]$}
\end{tabular}

TABle 3: Basic information of prefabricated projects cases.

\begin{tabular}{|c|c|c|c|c|c|c|c|c|}
\hline Project & $\begin{array}{c}\text { Number of } \\
\text { components } \\
\left(\mathrm{m}^{3}\right)\end{array}$ & $\begin{array}{l}\text { Unit } \\
\text { price } \\
\text { (yuan) }\end{array}$ & $\begin{array}{l}\text { Mechanical unit price } \\
\text { (yuan/machine-team) }\end{array}$ & $\begin{array}{l}\text { Artificial unit price } \\
\text { (yuan/man-days) }\end{array}$ & $\begin{array}{c}\text { The total cost } \\
\text { (ten thousand } \\
\text { yuan) }\end{array}$ & $\begin{array}{l}\text { Construction } \\
\text { period (month) }\end{array}$ & $\begin{array}{l}\text { Construction } \\
\text { area }\left(\mathrm{m}^{2}\right)\end{array}$ & $\begin{array}{l}\text { Prefabricated } \\
\text { rate }(\%)\end{array}$ \\
\hline Case 1 & 18181 & 2988 & 2000 & 100 & 5794.82 & 28 & 156806 & 15 \\
\hline Case 2 & 1628 & 2996 & 1800 & 93 & 759.28 & 28 & 11180 & 58 \\
\hline Case 3 & 2697 & 2991 & 2200 & 95 & 1209.12 & 38 & 16401 & 45 \\
\hline Case 4 & 1940 & 3427 & 1121 & 97 & 800.88 & 15 & 8383 & 40 \\
\hline Case 5 & 1377 & 3722 & 51 & 100 & 742.71 & 25 & 3584 & 15 \\
\hline
\end{tabular}

TABle 4: Construction cost fitting results.

\begin{tabular}{lccccc}
\hline & Case 1 & Case 2 & Case 3 & Case 4 & Case 5 \\
\hline Fitting cost (ten thousand yuan) & 5923.18 & 781.48 & 1125.35 & 730.20 & 789.21 \\
Actual cost (ten thousand yuan) & 5794.75 & 759.28 & 1209.11 & 800.88 & 740.11 \\
Difference (ten thousand yuan) & 128.42 & 22.20 & 83.76 & 70.68 & 49.10 \\
Deviation (\%) & 2.22 & 2.92 & 6.93 & 6.83 \\
\hline
\end{tabular}

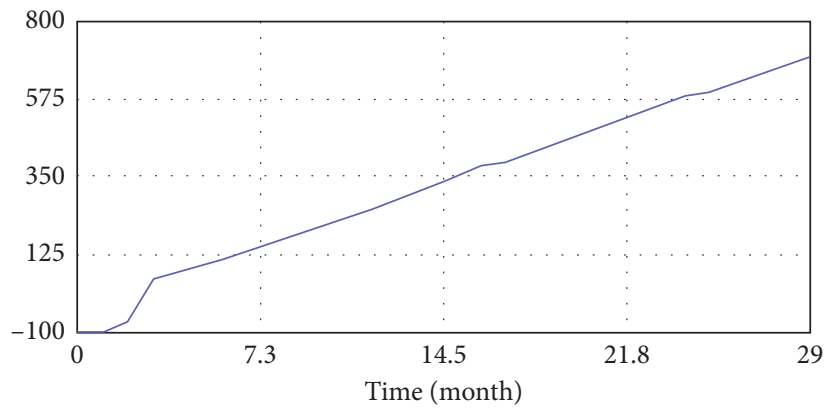

Figure 4: Project construction cost curve.

of components and reduce the unit price of components through scale effect.

Thirdly, the improvement of information technology level will bring significant impact on the reduction of costs. With BIM and the Internet of Things being the representative of the emerging information technologies and are widely used in the field of construction, they can greatly improve the precision and efficiency of design and construction. The semi-industrial production and construction method of prefabricated buildings is more conducive to the deep integration of industrialization and informatization, so that all parties involved in the project work together to 
TABLe 5: Sensitivity analysis table.

\begin{tabular}{|c|c|c|c|c|}
\hline Influencing factors & Rate of change (\%) & Construction costs & Sensitivity coefficient & The sorting \\
\hline \multirow[t]{2}{*}{ Current } & 0 & 652.78 & & \multirow{5}{*}{2} \\
\hline & -10 & 601.26 & 0.79 & \\
\hline \multirow{3}{*}{ Unit price } & -5 & 627.23 & 0.78 & \\
\hline & 5 & 677.93 & 0.77 & \\
\hline & 10 & 702.71 & 0.76 & \\
\hline \multirow{4}{*}{ Prefabricated rate } & -10 & 623.34 & 0.45 & \multirow{4}{*}{3} \\
\hline & -5 & 638.24 & 0.45 & \\
\hline & 5 & 667.08 & 0.44 & \\
\hline & 10 & 681.33 & 0.44 & \\
\hline \multirow{4}{*}{ Information technology level } & -10 & 661.19 & 0.13 & \multirow{4}{*}{4} \\
\hline & -5 & 656.87 & 0.13 & \\
\hline & 5 & 648.95 & 0.12 & \\
\hline & 10 & 645.44 & 0.11 & \\
\hline \multirow{4}{*}{ Degree of design standardization } & -10 & 649.02 & 0.06 & \multirow{4}{*}{1} \\
\hline & -5 & 650.90 & 0.06 & \\
\hline & 5 & 654.66 & 0.06 & \\
\hline & 10 & 656.55 & 0.06 & \\
\hline \multirow{4}{*}{ Mode of transport } & -10 & 655.76 & 0.05 & \multirow{4}{*}{5} \\
\hline & -5 & 654.27 & 0.05 & \\
\hline & 5 & 651.29 & 0.05 & \\
\hline & 10 & 649.79 & 0.05 & \\
\hline \multirow{4}{*}{ Artificial unit price } & -10 & 650.61 & 0.03 & \multirow{4}{*}{6} \\
\hline & -5 & 651.69 & 0.03 & \\
\hline & 5 & 653.86 & 0.03 & \\
\hline & 10 & 654.94 & 0.03 & \\
\hline \multirow{4}{*}{ Unit price of machinery } & -10 & 651.08 & 0.03 & \multirow{4}{*}{7} \\
\hline & -5 & 651.93 & 0.03 & \\
\hline & 5 & 653.63 & 0.03 & \\
\hline & 10 & 654.48 & 0.03 & \\
\hline \multirow{4}{*}{ Transport distance } & -10 & 652.31 & 0.01 & \multirow{4}{*}{8} \\
\hline & -5 & 652.54 & 0.01 & \\
\hline & 5 & 653.01 & 0.01 & \\
\hline & 10 & 653.25 & 0.01 & \\
\hline
\end{tabular}

TABLE 6: Results of influencing factors.

\begin{tabular}{lcccccccc}
\hline The sorting & 1 & 2 & 3 & 4 & 5 & 6 & 7 & 8 \\
\hline $\begin{array}{l}\text { Influencing } \\
\text { factors }\end{array}$ & $\begin{array}{c}\text { Degree of design } \\
\text { standardization }\end{array}$ & $\begin{array}{c}\text { Unit } \\
\text { price }\end{array}$ & $\begin{array}{c}\text { Prefabricated } \\
\text { rate }\end{array}$ & $\begin{array}{c}\text { Information } \\
\text { technology level }\end{array}$ & $\begin{array}{c}\text { Mode of } \\
\text { transport }\end{array}$ & $\begin{array}{c}\text { Artificial } \\
\text { level }\end{array}$ & $\begin{array}{c}\text { Mechanical } \\
\text { level }\end{array}$ & $\begin{array}{c}\text { Transport } \\
\text { distance }\end{array}$ \\
\hline
\end{tabular}

improve the efficiency and quality of construction and reduce costs.

In addition, transportation mode and transportation distance are the main factors affecting the cost of assembly construction. Due to the large volume of components and other reasons, logistics transportation will face great challenges, and it is necessary to make an appropriate plan for timely delivery and to carry out additional protection for loading and fixation of components during transportation [23], which will increase the construction cost. Transportation management mode needs to be further improved.

Finally, improvements in artificial machinery will contribute to cost savings in prefabricated buildings. Therefore, it is necessary to maintain the management control in the construction process to ensure the efficient operation of manual and mechanical work.

\section{Conclusions and Recommendations}

Prefabricated building construction cost is a dynamic complex system under the comprehensive influence of multiple factors. Based on the systematic analysis of the impact of prefabricated building cost, this paper establishes a model to simulate the impact of various factors on construction cost and draws the following conclusions: 
(1) The cost influencing factors of prefabricated buildings can be roughly divided into design, production, transportation, storage, construction, and installation, as well as other factors including information technology and management level. There are many correlations in the complex system composed of the above factors, thus forming the following important influence paths on cost: the design level will affect the design cost, the application of information technology will affect the design and management level, the level of labor and machinery will affect the installation costs, the transportation distance and mode will affect the transportation cost, and the component quality will affect the production cost. These ultimately affect construction costs.

(2) The cost control model can be established by using Vensim system dynamics software, and the running result of the system can be simulated by defining the relationship between the factors in the model. The deviation between the fitting result of the model and the actual project construction cost is within a reasonable range, which proves that the system dynamics model can be used as a cost control model for prediction and analysis.

(3) Through the simulation of the cost control model, the construction cost of the prefabricated building has been rising dynamically, the cost rises rapidly during the early stage (especially the design stage) and increases slowly during the construction period, and it is affected by quality, transportation, and other factors; the cost growth is volatile and unstable.

(4) According to the results of system simulation, the main cost influencing factors of prefabricated building include eight factors: unit price of components, prefabrication rate, information technology level, degree of design standardization, transportation mode, labor level, mechanical level, and transportation distance. Among them, the degree of design standardization is the most influential factor, followed by the unit price of components, the prefabrication rate, information technology level, transportation mode, labor level, mechanical level, and transportation distance.

(5) Based on the main influencing factors, prefabricated construction cost control should start from the macro perspective, improve the industrial chain, and increase the degree of market standardization. Further strengthen the application of BIM and other information technology, and improve the level of construction management, improve transportation process, and speed up the efficiency of artificial and mechanical application.

Therefore, the cost of prefabricated buildings in China can be further controlled from the following aspects:
(1) Improve the industrial chain and stimulate the market mechanism based on competition with strong policy support. The macro policy has always been a strong favorable factor. Under the guidance of the policy, more component factories have been established to form a favorable situation of scale, further promote the improvement of the upstream and downstream industry chain, give full play to the synergies of the whole industry chain, and carry out industrialization thoroughly. Prefabricated buildings have been an important achievement of the industrialization of buildings. Improving the industrial chain of prefabricated buildings and dividing the construction market more directly simply play a leading role in encouraging the market-oriented development of buildings. Further stimulate the market mechanism based on competition and promote the process of construction marketization. Therefore, under the background of industrialization, prefabricated building construction path is clearer, construction efficiency is further improved, and prefabricated building market is more prosperous.

(2) Combine BIM technology to improve the level of information technology. BIM technology has always been a focus of attention and development in the construction industry. The application of BIM technology will bring the improvement of design level, management level, and other aspects. Integrated delivery mode and intelligent technology application are two major trends of the future information development of prefab building. The development of prefab building driven by information will drive the industrial transformation of the future construction industry. The great value of information technology in prefab building, which vigorously promotes the development of prefab building through deep integration of building industrialization and information, will certainly inject new vitality into the transformation of the construction industry. It enables all parties involved in the construction of the project to work together better, realize the integration of green, industrialization and informatization in the construction industry, and make a big push towards the direction of intelligence, modernization and standardization. Through the use of information means to strengthen the component procurement, distribution, storage, and installation of fine, standardized management, the construction quality, cost, and progress of dynamic management can improve the assembly efficiency, and the construction quality.

(3) Adopt fine management strategy to fully control the production, transportation, and construction process. Based on the technical means of information 
technology, the process is effectively refined and decomposed by using the fine management concept. In view of the important influencing factors, such as unit price of components, transportation distance and mode of transportation, and the level of artificial machinery, strict control and continuous improvement measures are adopted to make cost control more detailed and standard. Under the background of the industrialization of prefabricated buildings, refined management will further bring the innovation of technical means, and the management efficiency is significantly improved.

There are still some deficiencies in this study. For example, the difficulty of cost control is not considered, and the cost control is not extended to the full life cycle. As the operation and maintenance period of China s prefabricated buildings continue, this will serve as the direction of indepth study. Since prefabricated buildings are always been the focus of national promotion, corresponding proposals on the development of prefabricated buildings have been put forward on the national two sessions. Therefore, we should continue to pay attention to the problems of prefabricated buildings.

\section{Data Availability}

Some or all data, models, or codes that support the findings of this study are available from the corresponding author upon reasonable request. The data, models, or codes are the data used to generate Figure 4 and Tables 4-6.

\section{Conflicts of Interest}

The authors declare that they have no conflicts of interest regarding the publication of this paper.

\section{Acknowledgments}

The authors wish to express their sincere gratitude to the Humanities and Social Sciences Research Program of the Ministry of Education (no. 19YJAZH026) for funding this research. Appreciation is also due to all members of the research team for their invaluable contributions.

\section{References}

[1] L. Zhao Kun, Q. Zhang, Y. Ji, and Z. Duan, "Evaluation of regional development level of prefabricated construction industry in China," Journal of Civil Engineering and Management, vol. 36, no. 1, pp. 59-65, 2019, in Chinese.

[2] X. Zhai, R. Reed, and A. Mills, "Factors impeding the offsite production of housing construction in China: an investigation of current practice," Construction Management and Economics, vol. 32, no. 1-2, pp. 40-52, 2013.

[3] Q. Lv, "Economic evaluation system model of prefabricated energy-saving buildings," Journal of Shenyang Jianzhu University (Social Science Edition), vol. 13, no. 3, pp. 303-306, 2011, in Chinese.
[4] Q. Jin, C. Xu, and X. Liu, "Research on factors affecting the life-circle cost of prefabricated building in China," ICCREM, vol. 2018, pp. 106-103, 2018.

[5] W. H. Tsai, S. J. Lin, J. Y. Liu, W. R. Lin, and K. C. Lee, "Incorporating life cycle assessments into building project decision-making: an energy consumption and $\mathrm{CO}_{2}$ emission perspective,” Energy, vol. 36, no. 5, pp. 3022-3029, 2011.

[6] Y. Qiu, H. Chen, Z. Sheng, and S. Cheng, "Governance of institutional complexity in megaproject organizations," International Journal of Project Management, vol. 37, no. 3, pp. 425-443, 2019.

[7] J. Zhang, H. Li, A. O. Olanipekun, and L. Bai, “A successful delivery process of green buildings: the project owners' view, motivation and commitment," Renewable Energy, vol. 138, pp. 651-658, 2019.

[8] T. N. Themsen, "The processes of public megaproject cost estimation: the inaccuracy of reference class forecasting," Financial Accountability \& Management, vol. 35, no. 4, pp. 337-352, 2019.

[9] B. Flyvbjerg, M. S. Holm, and S. Buhl, "Underestimating costs in public works projects: error or lie?" Journal of the American Planning Association, vol. 68, no. 3, pp. 279-295, 2002.

[10] P. Samani, J. Gregory, V. Leal, A. Mendes, and N. Correia, "Lifecycle cost analysis of prefabricated composite and masonry buildings: comparative study," Journal of Architectural Engineering, vol. 24, no. 1, pp. 501-7012, 2018.

[11] L. Li, B. Geng, B. Qi, Y. Lei, and L. A. N. Luan, "Cost comparison and Empirical Study of prefabricated building engineering and cast-in-place building engineering," Construction Economy, vol. 2013, no. 9, pp. 102-105, 2013, in Chinese.

[12] C. Liu and J. Chen, "Study on influence of prefabricated rate on the cost of prefabricated building," ICCREM, vol. 2019, pp. 554-561, 2019.

[13] J. Xie, D. Jiang, and P. Zhou, "Study on Prefabrication rate and cost of prefabricated shear wall structure system," Building Structure, vol. 48, no. 2, pp. 33-36, 2018, in Chinese.

[14] B. Anvari, P. Angeloudis, and W. Y. Ochieng, "A multi-objective GA-based optimisation for holistic manufacturing, transportation and assembly of precast construction," Automation in Construction, vol. 71, pp. 226-241, 2016.

[15] H. Hou, K. Wang, G. Du, Y. Mou, b. Qu, and J. Qi, "Life cycle cost analysis of prefabricated steel structures," Progress of Building Steel Structures, vol. 22, no. 3, pp. 121-128, 2020, in Chinese.

[16] A. W. Hammad, A. Akbarnezhad, P. Wu, X. Wang, and A. Haddad, "Building information modelling-based framework to contrast conventional and modular construction methods through selected sustainability factors," Journal of Cleaner Production, vol. 228, pp. 1264-1281, 2019.

[17] C. Cantarelli, B. van Wee, E. J. E. Molina, and B. Flyvbjerg, "Different cost performance: different determinants? The case of cost overruns in Dutch transport infrastructure projects," Transport Policy, vol. 22, pp. 88-95, 2012.

[18] Z. Shehu, I. R. Endut, A. Akintoye, and G. D. Holt, "Cost overrun in the Malaysian construction industry projects: a deeper insight," International Journal of Project Management, vol. 32, no. 8, pp. 1471-1480, 2014.

[19] J. O. Choi, J. T. O'Connor, and T. W. Kim, "Recipes for cost and schedule successes in industrial modular projects: qualitative comparative analysis," Journal of Construction Engineering and Management-Asce, vol. 142, no. 10, Article ID 4016055, 2016. 
[20] R. S. Heralova, "Life cycle cost optimization within decision making on alternative designs of public buildings," Procedia Engineering, vol. 85, pp. 454-463, 2014.

[21] S. Lee, S. Kim, and Y. Na, "Comparative analysis of energy related performance and construction cost of the external walls in high-rise residential buildings," Energy and Buildings, vol. 99, pp. 67-74, 2015.

[22] O. Pesämaa, J. Larsson, and P. E. Eriksson, "Role of performance feedback on process performance in construction projects: client and contractor perspectives," Journal of Management in Engineering, vol. 34, no. 4, Article ID 04018023, 2018.

[23] J. Hong, G. Q. Shen, Z. Li, B. Zhang, and W. Zhang, "Barriers to promoting prefabricated construction in China: a cost-benefit analysis," Journal of Cleaner Production, vol. 172, pp. 649-660, 2018.

[24] J.-H. Chen, L.-R. Yang, and H.-W. Tai, "Process reengineering and improvement for building precast production," Automation in Construction, vol. 68, pp. 249-258, 2016.

[25] R. Wang and C. Wang, "Key risk identification and Countermeasures of prefabricated building projects based on SNA," Journal of Shandong Agricultural University (Natural Science Edition), vol. 50, no. 2, pp. 72-75, 2019, in Chinese.

[26] N. Ham, S. Moon, J.-H. Kim, and J.-J. Kim, "Economic analysis of design errors in BIM-based high-rise construction projects: case study of haeundae L project," Journal of Construction Engineering and Management, vol. 144, no. 6, Article ID 05018006, 2018.

[27] B. Qi and Y. Zhang, "Research on development bottleneck and Countermeasures of prefabricated building," Journal of Shenyang Jianzhu University, vol. 17, no. 2, pp. 156-159, 2015, in Chinese.

[28] X. Li, G. Q. Shen, P. Wu, H. Fan, H. Wu, and Y. Teng, "RBLPHP: simulation of lean construction and information technologies for prefabrication housing production," Journal of Management in Engineering, vol. 34, no. 2, Article ID 04017053, 2018.

[29] Y. Zhong, X. Jia, and Y. Qian, System Dynamics, Science Press, Beijing, China, 2013, in Chinese.

[30] J. M. Lyneis, K. G. Cooper, and S. A. Els, "Strategic management of complex projects: a case study using system dynamics," System Dynamics Review, vol. 17, no. 3, pp. 237-260, 2001.

[31] X. Ning and Q. Wang, "Project time/cost estimation using system dynamics model," Science and Technology Guide, vol. 2003, no. 9, pp. 54-57, 2004, in Chinese.

[32] Q. He and M. Cheng, "Research on cost control of construction projects based on system dynamics," Journal of Wuhan Institute of Metallurgical Management, vol. 21, no. 2, pp. 26-29, 2011, in Chinese.

[33] J. Dong and R. Li, "Research about China's electricity market reform based on Hall's three dimensions structure model," American Journal of Electrical Power and Energy Systems, vol. 4, no. 4, pp. 51-56, 2015.

[34] L. Jia, Research on Cost Control of Prefabricated Building Project Based on System Dynamics, Qingdao University of Science and Technology, Qingdao, China, 2016, in Chinese.

[35] J. M. Juran and F. M. Gryna, Quality Planning and Analysis: From Product Development through Use, McGraw-Hill, New York, NY, USA, 2001. 